\title{
Recent breakthroughs in carrier depletion based silicon optical modulators
}

\author{
G. T. Reed ${ }^{1}$, G. Z. Mashanovich ${ }^{1}$, F. Y. Gardes ${ }^{1}$, M. Nedeljkovic ${ }^{1}$, Y. Hu ${ }^{1}$, D. J. Thomson ${ }^{1}$, L. \\ $\mathrm{Ke}^{2}$, P. Wilson ${ }^{2}, \mathrm{~S}-\mathrm{W}$. Chen ${ }^{3}$ and S. H. Hsu ${ }^{3}$. \\ 1 - Optoelectronics Research Centre, University of Southampton, Southampton, Hampshire, SO17 1BJ, UK. \\ 2 -School of Electronics and Computer Science, University of Southampton, Southampton, Hampshire, SO17 \\ $1 B J, U K$.
}

3 - High-Speed Devices and Integrated Circuits Group Department of Electrical Engineering, National Tsing Hua University, Hsinchu, Taiwan.

\begin{abstract}
The majority of the most successful optical modulators in silicon demonstrated in recent years operate via the plasma dispersion effect and are more specifically based upon free carrier depletion in a silicon rib waveguide. In this work we overview the different types of free carrier depletion type optical modulators in silicon. A summary of some recent example devices for each configuration is then presented together with the performance that they have achieved. Finally an insight into some current research trends involving silicon based optical modulators is provided including integration, operation in the mid-infrared wavelength based and application in longer haul data transmission links.
\end{abstract}

\section{Introduction}

The performance of silicon optical modulators has improved dramatically in recent years, coinciding with significant research effort from both academia and commercial organisations worldwide. The motivation for developing high performance optical modulators in silicon is clear. The optical modulator is central to the majority of photonics systems for datacom applications and silicon photonics provides a low cost platform in which to form these systems, making optical based communication feasible for a number of short reach links. Various mechanisms for achieving modulation in silicon have been investigated throughout the years. Excellent progress has been made in hybrid devices where other materials are incorporated with the SOI waveguides to achieve modulation, including group III-V materials ${ }^{1}$, germanium ${ }^{23456}$, polymers ${ }^{78}$ and graphene $e^{9} 111213$. Furthermore the plasmonic based approach is also interesting area to achieve modulation ${ }^{14} 1516$. This review will however focus on devices based upon the plasma dispersion effect and more specifically those using carrier depletion. Plasma dispersion effect devices are attractive as they can be formed using CMOS like processes making their integration into such fabrication facilities more straightforward. Employing carrier depletion as the mechanism to electrically modulate free carrier densities in the waveguide allows relatively simple fabrication whilst achieving high speed. Following 
a review of recent carrier depletion devices 252627282930313233343536373839414243444546474849505152 53545556575859 we will look more into the progress of their integration with other components.

\section{Performance metrics}

It is useful to start by considering the different performance metrics by which the devices can be assessed. For the phase modulator there are four core metrics: the optical loss and capacitance per unit length, the phase efficiency and the speed. Design choices over the passive structure used to house the phase modulator, the phase modulator length and the drive voltage then dictate what the overall performance of the modulator will be. For example for a Mach-Zehnder modulator, the use of a short phase modulator and a low drive voltage will result in low optical loss and low power consumption. However, the extinction ratio achieved will be lower. Conversely, if a larger extinction ratio is required either the phase modulator length or the drive voltage can be increased (or a combination of both), although this will result in an increase in optical loss or power consumption respectively. The different performance metrics for the overall modulator structure are listed below with description.

Modulator drive voltage/power consumption - The power consumption of the device is an important metric to consider particularly in applications which have multiple short-reach channels. The convention with silicon optical modulators is to report the power consumption in units of energy consumed per bit of data. The opinion of the power consumption targets varies throughout the field. Some state the other benefits that optical based interconnects bring could balance an increase power consumption compared to their electrical counterparts. The power consumption of a typical server has been reported as being on the order of $10-30 \mathrm{pJ} / \mathrm{bit}^{18}$ and therefore an improvement of an order of magnitude may not be essential to justify the added value of optical interconnects. When considering longer haul applications the power consumption of the device becomes less and less important. On the other hand some state that in order for silicon photonics based interconnects to be attractive, the power consumed should not be larger than electrical interconnects which they are proposed to replace $(\sim 1 \mathrm{pj} / \mathrm{bit})^{19}$. Some extend this argument stating that the energy should not exceed $100 \mathrm{fj} / \mathrm{bit}$ to surpass the efficiency of the $45 \mathrm{~nm}$ process node equalized on-chip electrical link $^{20}$. The optical modulator is not the only element in the system and therefore can only consume a proportion of this target power. Some state that the maximum power consumption for the modulator should therefore be on the order of $10 \mathrm{fj} / \mathrm{bit}^{21}$ which is clearly very demanding although some devices have shown potential ${ }^{22}{ }^{59}$. Ultimately the power consumption required is likely to be driven by the application in which the modulator is to be employed and will also determine the modulator configuration to be employed.

The power consumption of the device can be calculated in different ways depending on how it is driven: as a lumped element or with travelling wave electrodes. However, in both cases the drive voltage has a significant impact. Throughout this analysis we assume non-return-to-zero modulation. With the phase modulator incorporated into a Mach-Zehnder interferometer, a travelling wave electrode is typically used to allow for high speed operation over a long device. A termination resistance (usually $50 \mathrm{Ohms}$ ) is placed at the end of the travelling wave electrode to prevent reflection of the RF signal. Any power not consumed by the phase modulator will be dissipated in the termination and therefore the power consumption of the device will be dictated by the drive voltage, the impedance of the system and the bit rate. This is described by equation 1 where $V$ is the peak to peak drive voltage, $Z$ is the impedance of the system and $B R$ the bit rate.

$$
P=\frac{\left(\frac{V}{2}\right)^{2}}{Z \times B R} \quad \text { Equation } 1
$$


Carrier depletion modulators are essentially a diode operated in reverse bias and therefore a DC level is added to the RF signal to ensure that the drive voltage across the modulator remains negative. If a DC block is employed before the termination, equation 1 can still be used, otherwise equation 2 should be used where $V_{\max }$ and $V_{\min }$ are the voltages of the two data levels in the drive signal.

$$
P=\frac{V_{\max }^{2}}{2 \times Z \times B R}+\frac{V_{\min }^{2}}{2 \times Z \times B R} \quad \text { Equation } 2 .
$$

With the phase modulator incorporated into a resonant structure, for example a ring resonator, the modulator is driven as a lumped element with no additional termination element. In this case the capacitance and the drive voltage typically dictate the power consumption. This is described by equation 3 where $C$ is the capacitance of the device and $V$ the peak to peak drive voltage.

$$
P=\frac{C \times V^{2}}{4} \quad \text { Equation } 3 .
$$

It should be noted that typically a large reflection of the drive signal exists in the case of the ring. Conseuqently the drive voltage could be as much as double that applied to the device. This should be taken into account during the power calculations. Furthermore in the case of temperature sensitive devices such as ring resonators, an active tuning mechanism is typically required to ensure the modulator operating point is maintained with changes in device temperature. The power consumption of such a tuning mechanism should also be included in the calculation of the overall device performance. Alternatively different approaches have been demonstrated to make such structures athermal ${ }^{23} 24$.

Modulator loss - Aside from the phase modulator loss which is dictated by the loss per unit length and the length of phase modulator selected, there are contributions from the passive elements in the structure for example waveguide splitters, combiners and bends. The phase modulator loss comprises loss due to passive waveguide roughness, free carrier absorption due interaction with the different doped regions and any interaction with the electrode metal.

Modulation speed - This is often characterised either by its electro-optic bandwidth or its ability to modulate data at certain rates. The intrinsic speed of the phase modulator is governed by it's RC time constant, however, the design and resultant electrical performance of the electrodes can also significantly influence the device transient operation. In resonant devices the photon cavity lifetime can also place a limitation on the operating speed of the device.

Modulation phase efficiency - It is the amount of phase shift produced for a given phase shifter length and drive voltage. It is often reported in units of V.cm (the voltage required on a $1 \mathrm{~cm}$ long phase shifter to achieve a pi radian phase shift). Alternatively an effective index change per volt is sometimes reported. In the case of carrier depletion based devices the phase shift achieved with voltage is typically non-linear, reducing with increased reverse bias. The voltage at which the phase efficiency is measured should therefore be stated.

Modulation depth or extinction ratio - This is the difference in optical output power between the 1 and 0 levels of the modulator. As the modulation rate is increased the extinction ratio can be less than in the DC case (for the same applied voltage) if the electro-optic roll-off of the device prevents the optical response completely reaching the 1 and 0 power levels. The extinction ratio produced relates to the amount of phase shift achieved and ultimately dictates the bit error rate performance of the device.

Device footprint - It is the physical size of the modulator on the chip. Often in the case of MachZehnder devices this is reported as a length since this is the dominant dimension. In the case of the ring modulator, which is much more compact, the ring radius/diameter is usually stated. 
Optical bandwidth - This is the band of wavelengths for which the device can operate without any tuning of the device. For example in the case of a ring resonator based modulator, the device is operated in the resonance of the device and therefore the operating bandwidth is typically of about $<1 \mathrm{~nm}$. On the other hand symmetrical Mach-Zehnder based devices offer optical bandwidth larger than $80 \mathrm{~nm}$.

Temperature sensitivity - It shows how sensitive the device performance is to temperature changes. Since silicon has a relatively large thermo-optic coefficient $\left(1.8 \times 10^{4} \mathrm{~K}^{-1}\right)$, the optical response of passive structures such as ring resonators is sensitive to temperature changes. In a symmetrical Mach-Zehnder device, the temperature induced phase changes in either arm are balanced and therefore the device performance is not affected.

Chirp - This describes slight variations in modulator output wavelength during transitions between data levels. The result of this is dispersion in the fibre which dictates the maximum distance over which data at a specific rate can be transmitted. The majority of applications that silicon photonics is considered for are short-reach, and therefore chirp is not a concern., However, as performance improves, longer haul applications become more viable and chirp then needs to be considered. Chirp will be discussed in more detail in section 4.1.

\section{Design of carrier depletion modulators}

Silicon optical modulators based upon carrier depletion consist of a pn diode formed inside the optical waveguide, which under reverse bias conditions, depletes the waveguide of carriers and causes a change in refractive index and absorption. To produce intensity modulation it is more effective to use the phase response of the device and to employ a passive structure to convert between phase modulation and intensity modulation rather than to use the modulation of the absorption coefficient directly. The two most common structures are the Mach Zehnder Interferometer (MZI) and the ring resonator (RR) as discussed above. To some extent these structures will influence the overall performance of the devices. However, for this work we focus our analysis on the different types of carrier depletion based phase modulator elements.

There have been a wide variety of device designs reported in recent years, each of which can be generally categorised into one of three types. The first category of device is the one with a vertical pn junction similar to that shown in figure 1 (left). The second category of device has horizontal pn junction similar to the diagram in figure 1 (right). The final category has interleaved pn junctions (or interdigitated pn junctions). An example diagram of this type of device is shown in figure 2.
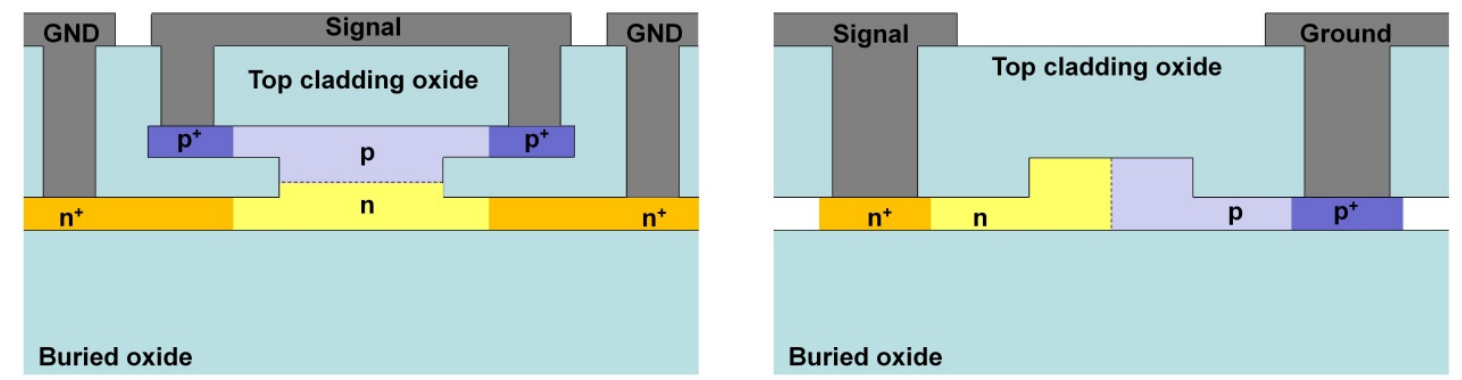

Figure 1 - Carrier depletion modulator with vertical junction (left) and horizontal junction (right). 


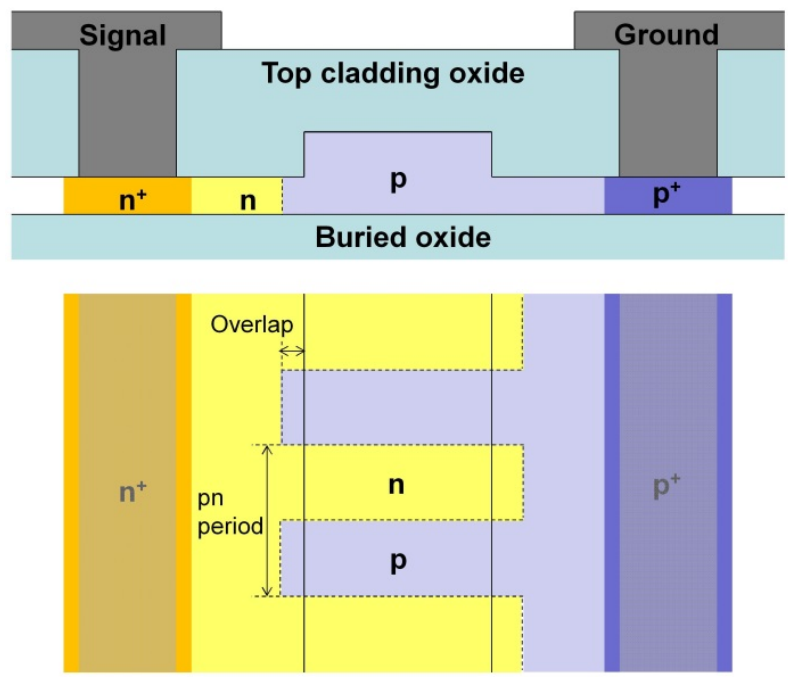

Figure 2 - Cross sectional (top) and plan (bottom) diagrams of interdigitated phase modulators.

Vertical junction devices have a pn junction which runs parallel to the top and bottom surfaces of the waveguide. The first proposed ${ }^{25}$ and demonstrated ${ }^{26}$ waveguide based carrier depletion modulators were of this type. The simulated performance by Gardes et al. ${ }^{25}$ demonstrated that modulation in the tens of $\mathrm{GHz}$ could be achieved in carrier depletion devices, which was a break through at that time ${ }^{25}$. Two years later the Intel Corporation demonstrated this version of the device experimentally with modulation at $30 \mathrm{Gbit} / \mathrm{s}$ presented ${ }^{26}$. Later $40 \mathrm{Gbit} / \mathrm{s}^{27}$ modulation was produced albeit with an extinction ratio of only $1 \mathrm{~dB}$. In their device the doping configuration was reversed compared to that shown in figure 1 and contact to the top section of the device was made on just one side of the waveguide. The concentration of the p-type region was $1.5 \mathrm{e} 17 . \mathrm{cm}^{-3}$ and the n-type region concentration varied from $1.5 \mathrm{e} 17 . \mathrm{cm}^{-3}$ at the junction to $3 \mathrm{e} 17 . \mathrm{cm}^{-3}$ at the top of the waveguide. A phase efficiency of $4 \mathrm{~V} . \mathrm{cm}$ was measured at $4 \mathrm{~V}$ with optical loss of $1.8 \mathrm{~dB} / \mathrm{mm}$.

\begin{tabular}{|c|c|c|c|c|c|c|c|c|c|c|}
\hline Ref. & $\begin{array}{l}\text { WG } \\
\text { width } \\
(\mathrm{nm})\end{array}$ & $\begin{array}{l}\text { WG } \\
\text { height } \\
\text { (nm) }\end{array}$ & $\begin{array}{c}\text { Slab } \\
\text { height } \\
(\mathrm{nm})\end{array}$ & $\begin{array}{l}\text { P conc. } \\
\left(. \mathrm{cm}^{-1}\right)\end{array}$ & $\begin{array}{l}\mathrm{N} \text { conc. } \\
\left(. \mathrm{cm}^{-1}\right)\end{array}$ & $\begin{array}{l}\mathrm{P}+, \mathrm{N}+\text { to WG } \\
\text { separation } \\
(\mathrm{nm})\end{array}$ & $\begin{array}{c}\text { Efficiency } \\
\text { (V.cm) }\end{array}$ & $\begin{array}{l}\text { Loss } \\
\text { (dB/ } \\
\mathrm{mm} \text { ) }\end{array}$ & $\begin{array}{c}\text { Capacitance } \\
\text { (fF/um) }\end{array}$ & $\begin{array}{l}\text { Speed } \\
\text { (Gb/s) }\end{array}$ \\
\hline 31 & 480 & 300 & 80 & $4 \mathrm{e} 18$ & $4 e 18$ & - & - & $7-8$ & - & 40 \\
\hline 32 & 500 & 220 & 90 & $5 e 17$ & $5 e 17$ & 950 & $\begin{array}{c}1.9 \\
(@ 3 V)\end{array}$ & 1.2 & $0.3-0.4$ & 50 \\
\hline 33 & 500 & 220 & 90 & $7 \mathrm{e} 17$ & $5 e 17$ & 950 & $\begin{array}{c}3.5 \\
(@ 3 V)\end{array}$ & $1^{*}$ & 0.27 & 20 \\
\hline 34 & 500 & 220 & 150 & $2 \mathrm{e} 18$ & $2 \mathrm{e} 18$ & - & - & - & - & 35 \\
\hline 35 & 500 & 220 & 150 & $1 \mathrm{e} 18$ & $1 \mathrm{e} 18$ & 1000 & $\begin{array}{c}1.7 \\
(@ 4 V)\end{array}$ & 2.2 & - & 12.5 \\
\hline 36 & 500 & 220 & 100 & $1 \mathrm{e} 18$ & $3 \mathrm{e} 18$ & - & $\begin{array}{c}1.59 \\
\text { (Linear) }\end{array}$ & 3.2 & 0.84 & 30 \\
\hline 37 & 450 & 340 & 80 & $2 \mathrm{e} 17$ & $2 \mathrm{e} 17$ & 1000 & $\begin{array}{c}1.7 \\
(@ 3 V)\end{array}$ & $1.2^{*}$ & - & 30 \\
\hline 38 & 500 & 220 & 150 & $1 \mathrm{e} 18$ & $1 \mathrm{e} 18$ & 1000 & $\begin{array}{c}2 \\
(@ 3 V)\end{array}$ & 2.3 & 0.5 & 10 \\
\hline 38 & 500 & 220 & 150 & $2 \mathrm{e} 18$ & $2 \mathrm{e} 18$ & 1000 & $\begin{array}{c}1.2 \\
(@ 3 V)\end{array}$ & 4.5 & & 40 \\
\hline $39^{\Delta}$ & 400 & 220 & 70 & $1 \mathrm{e} 18$ & $8 \mathrm{e} 17$ & 1000 & $\begin{array}{c}1.3 \\
\text { (@0.8V) }\end{array}$ & 2.3 & - & 26 \\
\hline
\end{tabular}

*Excludes passive waveguide loss. ${ }^{\triangle}$ Intrinsic gap of $80 \mathrm{~nm}$ between $\mathrm{p}$ and $\mathrm{n}$ regions is used to reduce capacitance.

Table 2 - Comparison of horizontal pn junction modulators with the pn junction positioned in the centre of the device.

Horizontal junction devices where the pn junction runs perpendicular to the top and bottom surfaces of the waveguide are a lot more common. The first designs of this type were demonstrated in $2008^{282930}$, and since then there have been numerous versions published with different variants 
in the design 323334353637384143444531 . The most straightforward form of the device has the pn junction positioned in the waveguide equidistant from the rib edges 3233343536373839 . Table 2 summarises the design parameters and performances of some example horizontal junction devices demonstrated recently.

The table focuses on the performance of the phase modulator rather than the overall modulator structure and therefore the device speed can be a little misleading since as described in the previous section this is dependent on more factors than just the phase modulator itself. As can be seen in table 2 even with the horizontal design selected and the pn junction position fixed in the middle of the waveguide there are still many design parameters which can be changed in order to optimise certain performance metrics. Firstly the rib waveguide geometry in terms of its height, width, slab height and sidewall angle can be varied (although in most processes the sidewall angle is fixed at 90 degrees). When selecting which waveguide dimensions to use there are different factors that should be considered. Firstly, the waveguide should support only single mode propagation to avoid performance degradation in interferometric and resonant structures. Secondly, if polarisation independence is required without a polarisation diversity scheme, the dimensions should be chosen to support both fundamental TE and TM modes and the effective index and optical loss for both modes should be the same ${ }^{46}$. The waveguide geometry also affects the confinement of the optical mode within the waveguide and therefore the degree of interaction with the region of changing refractive index (depletion region). Ultimately the optical mode confinement affects the phase efficiency of the device but also a well confined mode is likely to mean that interaction with the highly doped regions positioned away from the waveguide can be reduced, benefiting optical loss due to absorption from free carriers. The height of the slab influences the access resistance to the pn junction and therefore the speed of the device. A thick slab therefore lends itself to a higher speed. Interaction of the optical mode with side wall roughness is also reduced and consequently scattering losses can be reduced. On the other hand a thick slab region causes high losses in waveguides bends such as those required in Mach-Zehnder Interferometers and ring resonators.

The next consideration is the concentration and positioning of the different doped regions. The distance separating the waveguide rib and the highly doped regions affects the access resistance to the device and the interaction with the optical mode. In terms of performance this translates into device speed and optical loss. Close proximity of these regions to the waveguide will reduce access resistance to the device and therefore facilitates high speed operation, however it will also result in an increased loss. The doping concentration of the highly doped regions should be high enough to allow ohmic contacts to be formed with the device electrodes as well as providing low access resistance to the junction. The concentration of the lower dose regions influences many of the performance metrics including optical loss, phase efficiency, speed and capacitance. High doping concentrations generally provide a reduced access resistance and higher junction capacitance. It's effect on the overall RC time constant could therefore be positive or negative depending on the design, however if the junction is correctly positioned it will allow for a higher efficiency since a greater change in free carrier concentration will interact with the core of the optical. The down-side to a high doping concentration is the increase in absorption loss and capacitance.. There therefore exists another trade-off which can also be used to tailor the device performance towards a profile of metrics as required.

Finally the design of the electrodes is a very important consideration to optimise the speed of the device. For MZI based devices coplanar waveguide electrodes (CPW) are normally employed with the diode connected between the signal track and the ground plane to one of the sides. In order to minimise reflection losses of the drive signal these electrodes should be designed to have a characteristic impedance which is matched to that of the drive equipment (usually $50 \mathrm{Ohms}$ ) with the effect of the pn diode on the CPW impedance taken into account. The electrodes should also be designed such that the velocity of the electrical signal is matched to the velocity of the light in the 
waveguide. Any velocity mismatch will mean that the drive signal will not act on the same portion of light in time causing a limitation on the device speed as highlighted in the slow wave device reported by Brimont et al. ${ }^{40}$. RF propagation loss should be minimised. High frequency components experience greater attenuation than low frequency components meaning that the electrodes will have a limited bandwidth for which signals can be transmitted. A longer electrode will have a lower bandwidth and this means it can be difficult to achieve a large extinction ratio together with high speed due to electrode based bandwidth limitations.

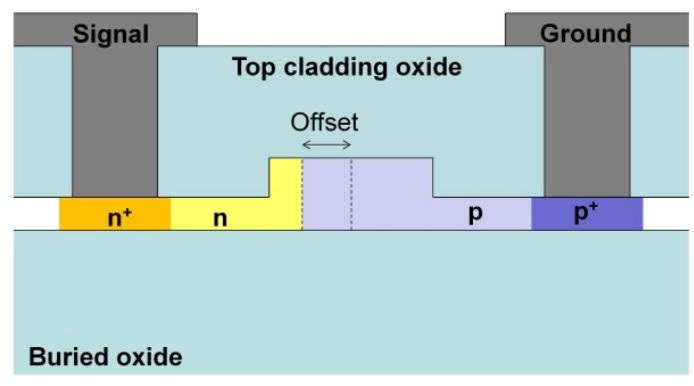

Figure 3 -Cross-sectional diagram horizontal device with offset pn junction.

Previously we have only considered devices with the pn junction fixed equidistant from the rib edges, but clearly the position of this pn junction is another parameter which can be varied. Some research groups have looked at offsetting the pn junction as shown in figure 3 and have stated that an improvement in performance results ${ }^{3041442}$. Table 3 summarises the design parameters used and performance of these phase modulators.

\begin{tabular}{|c|c|c|c|c|c|c|c|c|c|c|c|}
\hline Ref. & $\begin{array}{l}\text { WG } \\
\text { width } \\
\text { (nm) }\end{array}$ & $\begin{array}{l}\text { WG } \\
\text { height } \\
\text { (nm) }\end{array}$ & $\begin{array}{c}\text { Slab } \\
\text { height } \\
(\mathrm{nm})\end{array}$ & $\begin{array}{c}P \\
\text { conc. } \\
\left(. \mathrm{cm}^{-1}\right)\end{array}$ & $\begin{array}{c}\mathrm{N} \\
\text { conc. } \\
\left(. \mathrm{cm}^{-1}\right)\end{array}$ & $\begin{array}{c}\text { Offset } \\
\text { towards } n+ \\
\text { side }(\mathrm{nm})\end{array}$ & $\begin{array}{c}\mathrm{P}+, \mathrm{N}+\text { to WG } \\
\text { separation } \\
(\mathrm{nm})\end{array}$ & $\begin{array}{c}\text { Efficiency } \\
\text { (V.cm) }\end{array}$ & $\begin{array}{l}\text { Loss } \\
\text { (dB/ } \\
\mathrm{mm})\end{array}$ & $\begin{array}{c}\text { Capacitance } \\
\text { (fF/um) }\end{array}$ & $\begin{array}{l}\text { Speed } \\
\text { (Gb/s) }\end{array}$ \\
\hline 30 & 600 & 600 & 200 & $2 \mathrm{e} 18$ & $3 e 17$ & Negative & - & 14.3 & - & - & 12.5 \\
\hline 44 & 300 & 200 & 50 & 2e17 & $6 e 17$ & 75 & 1000 & 11 (@3V) & - & - & $19 *$ \\
\hline 41 & 450 & 340 & 80 & $2 \mathrm{e} 17$ & $2 \mathrm{e} 17$ & 50 & 1000 & 1.8 (@3V) & 1.6 & - & 60 \\
\hline 42 & 220 & 600 & 60 & $1 \mathrm{e} 17$ & 1e17 & $50^{\Delta}$ & 500 & $\begin{array}{c}1.5 \text { (0 to } \\
6 \mathrm{~V})\end{array}$ & 1.5 & - & 12 \\
\hline
\end{tabular}

${ }^{*}$ This is a bandwidth measurement of $19 \mathrm{GHz}$ rather that a data rate measurement. ${ }^{\Delta}$ In this case the edge of the $\mathrm{n}$-type region is offset $50 \mathrm{~nm}$ however the edge of the p-type is not offset, therefore there is a $50 \mathrm{~nm}$ intrinsic region.

Table 3 - Comparison of horizontal pn junction modulators with the pn junction positioned offset from the centre of the waveguide rib.

It can be seen that usually the offset is such that the majority of the rib is formed of $p$-type material. This is because a larger refractive index change and lower absorption loss can be achieved with $p$ type than with $n$-type material as described in the expressions produced by Soref and Bennett ${ }^{71}$. Interestingly You et al. used a negative offset ${ }^{30}$ giving the explanation that electron depletion leads to a faster electrical response than hole depletion does and therefore a faster device should result.

Since only the electrically varying depletion region within the rib waveguide contributes to the modulation of the refractive index whereas the entire doped region contributes to the optical loss some research groups have considered how the doping is localised in the waveguide with the aim of reducing optical absorption losses whilst maintain phase efficiency and device speed. For example in the device of Marris-Morini et al. a p-type doped slit was positioned in the core of the optical mode with the remainder of the waveguide rib left largely undoped ${ }^{29}$. In this way optical absorption losses due to the interaction with doping around the edges of the waveguide which does not deplete during biasing is avoided. A cross-sectional depiction of this device is shown in the left of figure 4. A loss of $1 \mathrm{~dB} / \mathrm{mm}$ occurred in this case with a phase efficiency of $3.5 \mathrm{~V} . \mathrm{cm}$. The authors were also able to demonstrate $40 \mathrm{Gbit} / \mathrm{s}$ modulation ${ }^{51}$. In a similar concept Tu et al. ${ }^{43}$ used a doping compensation 
method to reduce the concentration of free carriers in the upper sides of the rib (as depicted in the right hand image of figure 4). An optical loss of less than $1 \mathrm{~dB} / \mathrm{mm}$ was reported with a phase efficiency of around $2.67 \mathrm{~V} . \mathrm{cm}$. Modulation up to $50 \mathrm{Gbit} / \mathrm{s}$ was reported.
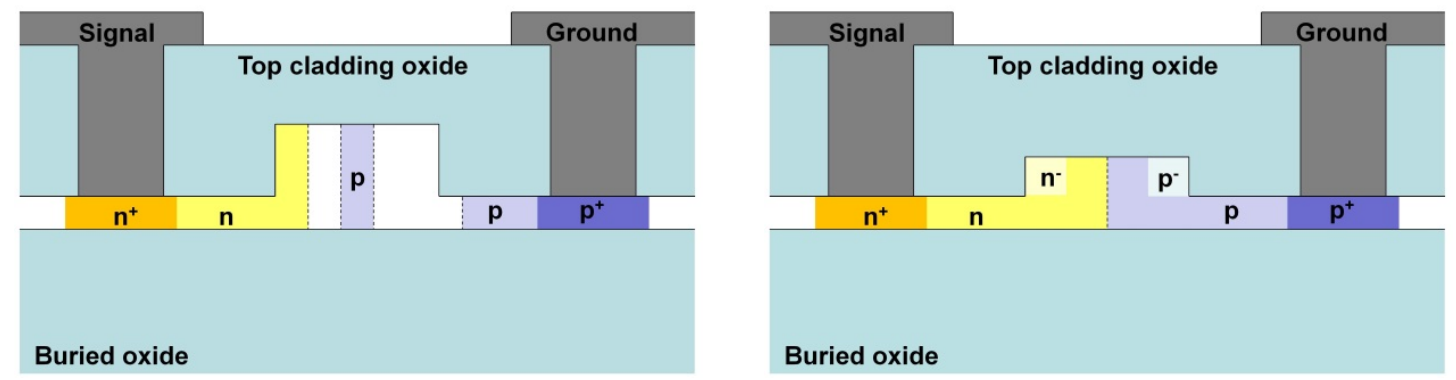

Figure 4 - Cross-sectional diagram of device by Marris-Morini et al. (left) ${ }^{29}$ and Tu et al. (right) ${ }^{43}$

Another consideration in the design of the device is the accuracy with which the fabrication tools can position the pn junction within the rib waveguide. A study by Gardes et al. into the extent which misalignment of the pn junction could affect device performance showed that the phase efficiency could be reduced by more than $40 \%$ with just $50 \mathrm{~nm}$ misalignment ${ }^{44}$ as shown in figure 5 .

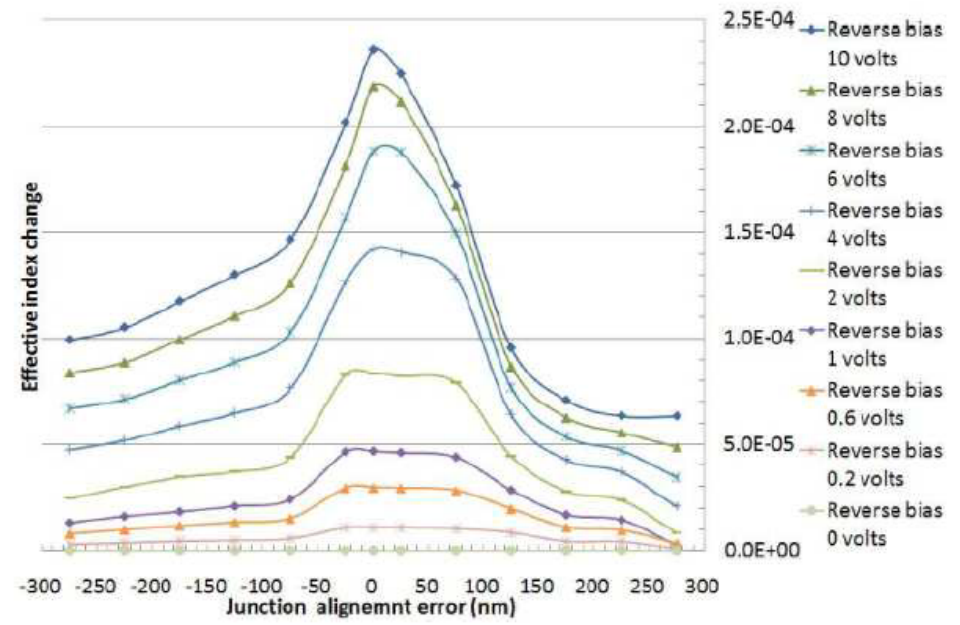

Figure 5 - Theoretical study of effective index change against pn junction alignment error ${ }^{44}$.

To overcome this issue and to therefore create a design which is robust to fabrication errors and therefore results in a high yield, a fabrication process using self-aligned pn junction formation has been devised ${ }^{45}{ }^{46}$. The process used by Thomson et al. is shown in figure 6. Firstly the active areas of the wafer are implanted with boron to form background p-type doping. Next the waveguide design is etched into a silicon dioxide hard mask layer which has been deposited onto the wafer surface. This hard mask is used to etch the waveguide design into the silicon overlayer and then together with a photoresist layer it is used to guide the phosphorus implant which produces the n-type regions. Either the hard mask or the photoresist layer are sufficiently thick to prevent penetration of the phosphorus ions into the silicon overlayer and therefore the edge of the photoresist window can be aligned with low accuracy on top of the waveguide with the resultant pn junction positioned precisely at the edge of the waveguide. The remainder of the process can be performed using standard CMOS like processing steps. Using this simple process the phase modulator with cross section as shown in figure 7 has been produced. 

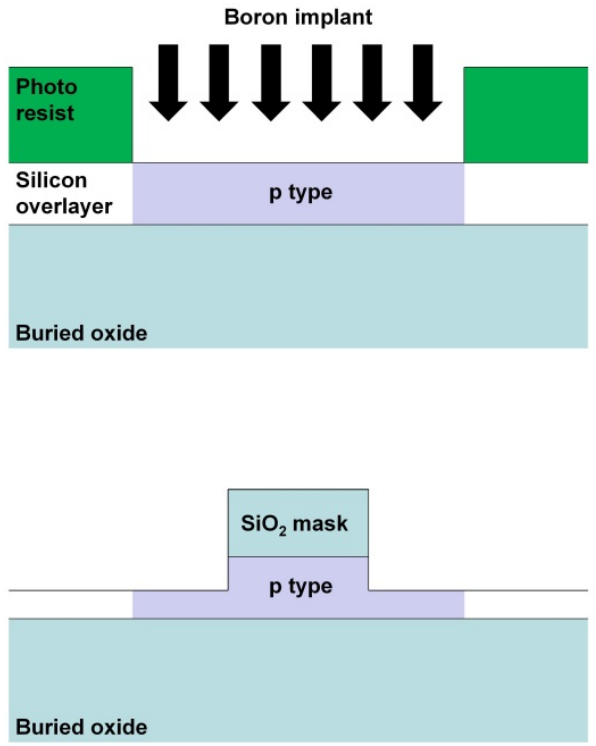

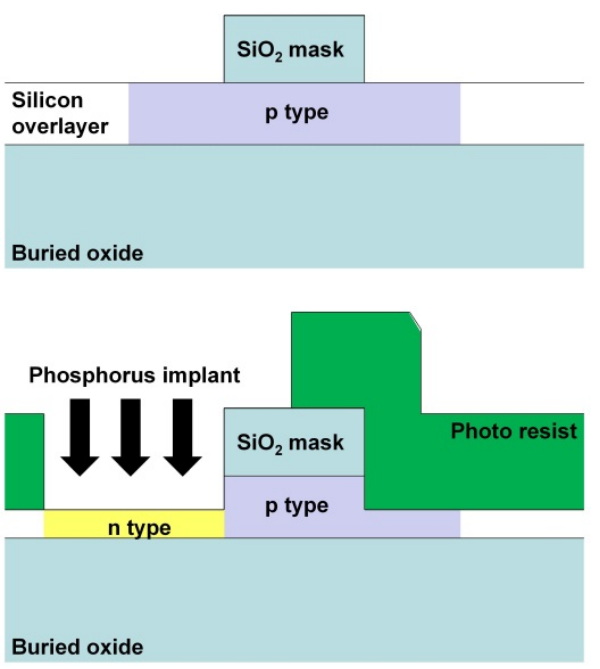

Figure 6 - Diagram showing the self-aligned formation of the pn junction. Firstly the active region is doped $p$ type (top left). A silicon dioxide layer is the deposited and patterned with the waveguide design (top right). This patterned silicon dioxide layer is then used as a hard mask through which to etch the waveguides (bottom left).

Finally the silicon dioxide hard mask is used together with a photoresist window to define the phosphorus implantation region ${ }^{45}$.

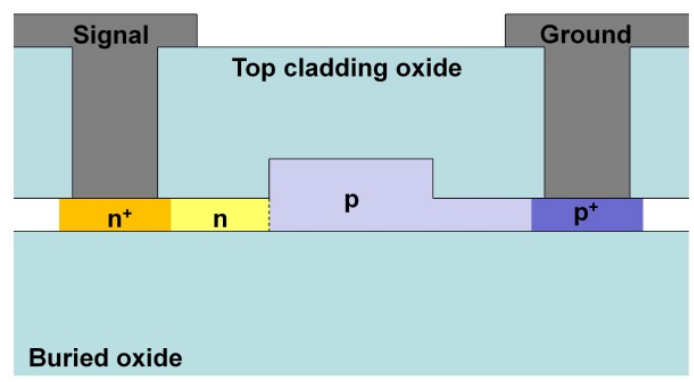

Figure 7-Cross sectional diagrams of phase modulators produced using the self-aligned process ${ }^{45}$.

As the pn junction is positioned at the edge of the waveguide the doping concentration of the $n$-type region $\left(1.5 \mathrm{e} 18 . \mathrm{cm}^{-3}\right)$ is made much higher than that of the $\mathrm{p}$-type region $\left(3 \mathrm{e} 17 . \mathrm{cm}^{-3}\right)$ so that the depletion extends mainly into the waveguide during biasing. This approach allows for a large phase shift with voltage with a peak efficiency figure of $2.3 \mathrm{~V} . \mathrm{cm}$ demonstrated so $\mathrm{far}^{47}$. In a different variant of the device modulation at $40 \mathrm{Gbit} / \mathrm{s}$ with $10 \mathrm{~dB}$ extinction ratio ${ }^{48}$ and $50 \mathrm{Gbit} / \mathrm{s}$ with a $3 \mathrm{~dB}$ extinction ratio ${ }^{49}$ has been demonstrated from $3.5 \mathrm{~mm}$ long and $1 \mathrm{~mm}$ long phase shifters of efficiency $\sim 2.7 \mathrm{~V} . \mathrm{cm}$, respectively. The optical loss in the phase modulator is $4 \mathrm{~dB} / \mathrm{mm}$ excluding passive waveguide loss, with the largest contribution coming from the interaction with the highly doped regions. It was later shown that by increasing the separation of these regions from the waveguide by $100 \mathrm{~nm}$ the optical loss could be reduced to $1.1 \mathrm{~dB} / \mathrm{mm}$ with little impact on the device speed and efficiency ${ }^{47}$. By angling the implantation in the final step of the self-aligned process as shown in left image of figure 8 the junction can be accurately positioned inside the waveguide. Gardes et al. used this variant of the process to produce the phase modulator shown in the right of figure $8^{46}$. 

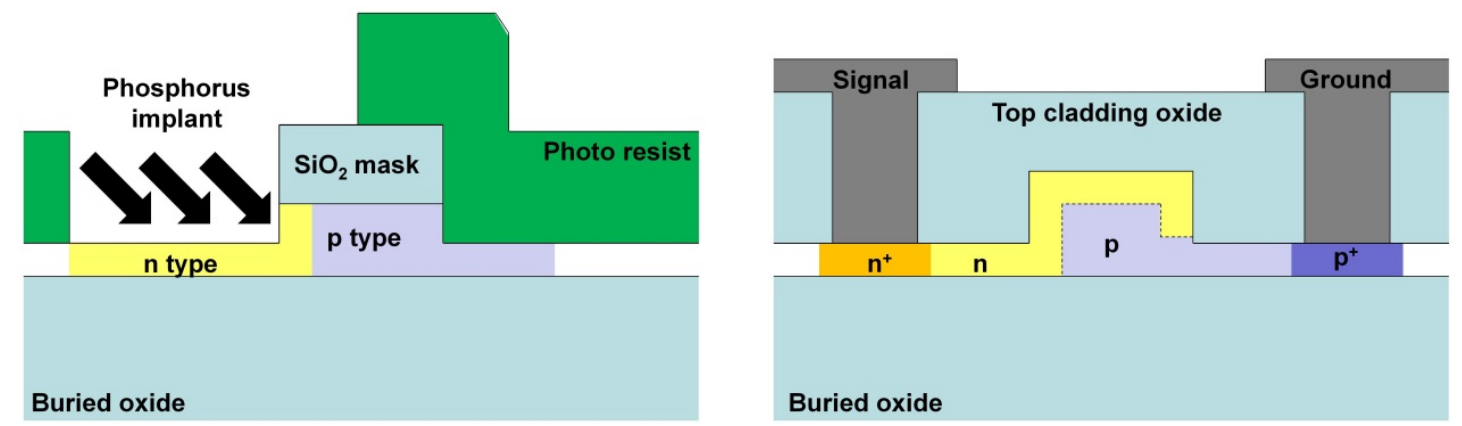

Figure 8-Diagram showing how ions implanted at an angle can be used to position the pn junction within the rib waveguide whilst using a self-aligned fabrication process ${ }^{46}$.

The aim of this device was to achieve polarisation independence from a device formed with a selfaligned process. The different sections of $n$-type doping allowed more degrees of freedom to balance the phase efficiencies for the fundamental TE and TM modes. Modulation at $10 \mathrm{Gbit} / \mathrm{s}$ and $40 \mathrm{Gbit} / \mathrm{s}$ was demonstrated with the same extinction ratio for both polarisations $(7.3 \mathrm{~dB}$ and $6.5 \mathrm{~dB}$ respectively). Recently other research groups have also used the same self-aligned angled ion implantation approach ${ }^{50}$. Furthermore it was also later reported that the device of Marris-Morini et al. could also be formed using a self-aligned process ${ }^{51}$. The device of Gardes et al. is a slightly different category of device which combines different pn junction types, in this case the vertical and horizontal pn junctions. This further category of device will be revisited later in this paper. The interdigitated/interleaved category of devices can also be free of alignment errors. A diagram of a typical device of this type was shown in figure 2.

In this case the cross sectional diagram alone does not reveal the design of the junction however in the plan view the sections of $p$-type and n-type doping along the waveguide can be seen. Theoretically very high modulation efficiencies can be achieved with this type of device since the relative density of depletion region in the waveguide is higher than in the other two categories of device if the period of the $p$-type and n-type regions is small. With this increase in depletion volume comes an increase in capacitance per unit length which can be detrimental in terms of device speed and power consumption. As mentioned above, tolerance to alignment errors is possible with this structure. It can be achieved if the overlap of the doped regions with the waveguide is larger than the optical mode plus the alignment accuracy of the tools used to fabricate the device. The negative impact of increasing the overlap is again the increased capacitance per unit length. The first of such devices was proposed in 2009 by $L i$ et al. $^{52}$. Recently there has also been some experimental demonstrations of modulation from interleaved devices as summarised in table $4{ }^{53545538}$.

\begin{tabular}{|c|c|c|c|c|c|c|c|c|c|c|c|c|}
\hline Ref. & $\begin{array}{l}\text { WG } \\
\text { width } \\
\text { (nm) }\end{array}$ & $\begin{array}{c}\text { WG } \\
\text { height } \\
\text { (nm) }\end{array}$ & $\begin{array}{c}\text { Slab } \\
\text { height } \\
(\mathrm{nm})\end{array}$ & $\begin{array}{c}P \\
\text { conc. } \\
\left(. \mathrm{cm}^{-1}\right)\end{array}$ & $\begin{array}{c}\mathrm{N} \\
\text { conc. } \\
\left(. \mathrm{cm}^{-1}\right)\end{array}$ & $\begin{array}{c}\text { PN } \\
\text { period } \\
(\mathrm{nm})\end{array}$ & $\begin{array}{c}\text { Overlap } \\
\text { (nm) }\end{array}$ & $\begin{array}{l}\mathrm{P}+, \mathrm{N}+\text { to } \\
\text { WG } \\
\text { separation } \\
(\mathrm{nm})\end{array}$ & $\begin{array}{c}\text { Efficiency } \\
\text { (V.cm) }\end{array}$ & $\begin{array}{l}\text { Loss } \\
\text { (dB/ } \\
\mathrm{mm})\end{array}$ & $\begin{array}{l}\text { Capacitance } \\
\text { (fF/um) }\end{array}$ & $\begin{array}{l}\text { Speed } \\
\text { (Gb/s) }\end{array}$ \\
\hline 53 & 450 & 340 & 80 & $2 \mathrm{e} 17$ & 2e17 & 600 & 0 & 1000 & 1.7 (@3V) & 1 & 0.65 & 44 \\
\hline 54 & 500 & 340 & 80 & $2 \mathrm{e} 17$ & $2 \mathrm{e} 17$ & 600 & 100 & 500 & 1.4 (@3V) & 1.7 & 0.34 & 25 \\
\hline 55 & 420 & 390 & 100 & $4 \mathrm{e} 17$ & $1 \mathrm{e} 18$ & $700^{*}$ & 0 & - & 3 (@3V) & - & 0.2 & 10 \\
\hline 38 & 500 & 220 & 150 & $2 \mathrm{e} 18$ & $2 \mathrm{e} 18$ & 500 & 550 & 1000 & 0.8 (@4V) & 3.5 & 1.6 & 10 \\
\hline
\end{tabular}

Table 4-Comparison of interleaved/interdigitated pn junction modulators.

A further approach as briefly mentioned above is a junction design which encompasses a combination of vertical, horizontal and interleaved sections. A device with a combination of horizontal and interleaved junctions can be achieved if a negative overlap with the waveguide is 
used. In this case a horizontal junction exists on the sides of the interleaved doped regions. This approach may enable optimising a trade-off of efficiency and capacitance; however it will now be sensitive to alignment errors in the fabrication. Another way to achieve a combination of horizontal and interleaved junctions is to have a zigzag shape running along the waveguide as demonstrated in a device by Xiao et al. ${ }^{56}$ and is depicted in figure 9 .

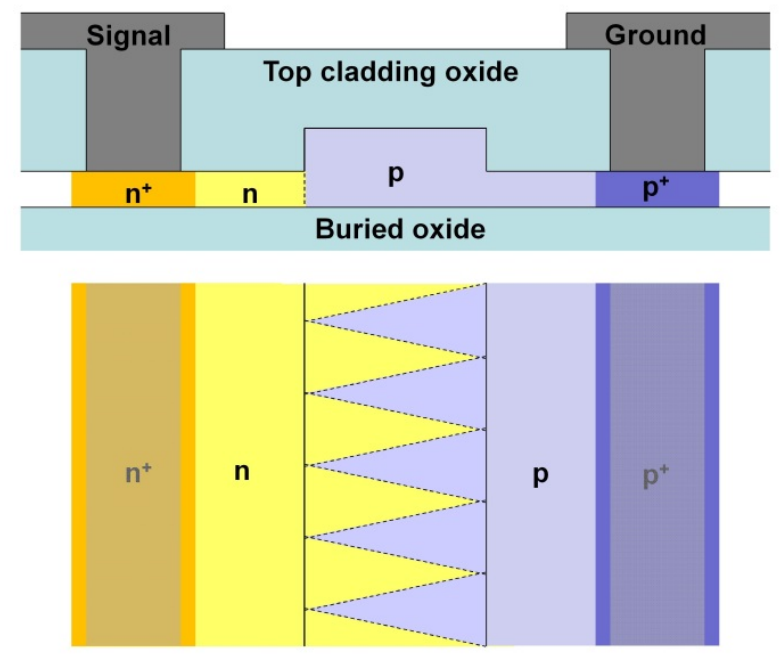

Figure 9 -Cross sectional (top) and plan (bottom) diagrams of zigzag phase modulators ${ }^{56}$.

Their device was based in rib waveguides of height $340 \mathrm{~nm}$, width $500 \mathrm{~nm}$ and slab height $80 \mathrm{~nm}$. The doping concentrations of the p-type and $n$-type regions was $2 \mathrm{e} 17 . \mathrm{cm}^{-3}$, whilst the separation between the highly doped regions and the rib edge was $500 \mathrm{~nm}$. With this approach the authors reported a phase efficiency of $1.7 \mathrm{~V} . \mathrm{cm}$ with modulation up to $44 \mathrm{Gbit} / \mathrm{s}$. The capacitance of the phase modulator was approximately $0.7 \mathrm{fF} / \mu \mathrm{m}$, however the optical loss due to the phase modulator was not reported.

As mentioned when discussing the device of Gardes et al. ${ }^{46}$ as shown in figure 7 (right) it is also possible to combine vertical and horizontal junction type devices. Such an approach has also been proposed by Spector et al. ${ }^{57}$ and demonstrated recently by Liow et al. ${ }^{50}$. The device of Liow et al. was similar to that shown in figure 7 without the n-type region on the right hand rib edge. The authors motivation for this design was to produce a device with a vertical junction without requiring a top contact. The authors compared a horizontal junction device and this device achieving phase efficiencies of $2.56 \mathrm{~V} . \mathrm{cm}$ and $1.12 \mathrm{~V} . \mathrm{cm}$ respectively, which demonstrates the advantage of this approach.

Resenberg et al. recently presented a device that combines vertical, horizontal and interleaved junctions as depicted in figure $10^{58}$. The doping densities of the $p$ and n-type regions was $2 \mathrm{e} 18 . \mathrm{cm}^{-3}$, the period of the interleaving $560 \mathrm{~nm}$ and the width of the p-type region on the left edge of the waveguide $100 \mathrm{~nm}$. The target thickness of the p-type region at the top of the rib was $110 \mathrm{~nm}$. With this device the authors achieved an impressive phase efficiency of $0.84 \mathrm{~V} . \mathrm{cm}$ for $-2 \mathrm{~V}$ reverse bias. A capacitance of $0.65 \mathrm{fF} / \mathrm{um}$ was reported with an optical loss of $3.5 \mathrm{~dB} / \mathrm{mm}$. Optical eye diagrams up to $40 \mathrm{Gbit} / \mathrm{s}$ were presented. 


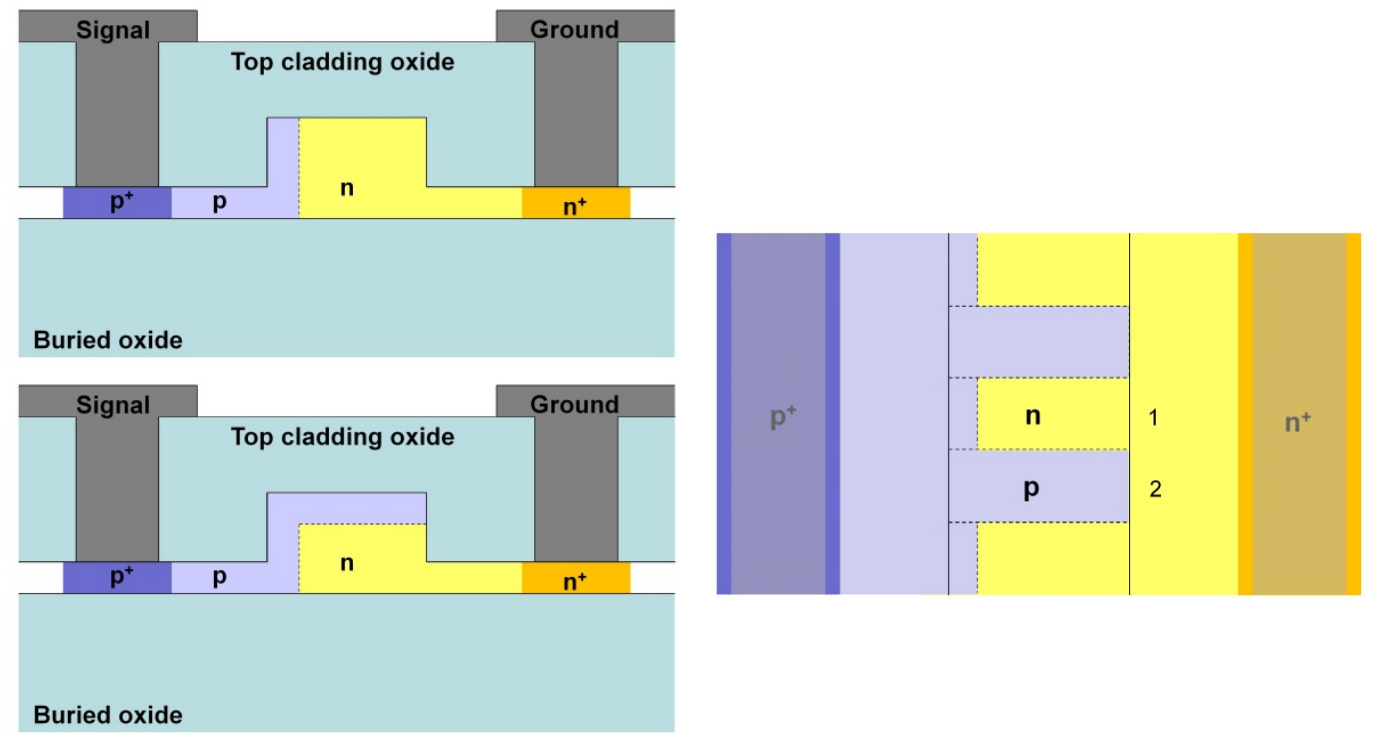

Figure 10 - Cross sectional diagrams of section 1 (top left) and section 2 (bottom left) and plan view (right) of phase modulator with vertical, horizontal and interleaved pn junctions ${ }^{58}$.

To summarise this section the merits and shortcomings of each approach will be discussed.

One disadvantage of the purely vertical structure is the need to electrically contact to both the top and the base of the waveguide, meaning that a conventional rib waveguide structure cannot be used. A slab section is required on at least one side of the top section of the waveguide. Hence the formation of this device therefore used a silicon growth process which would not be required with the other configurations of carrier depletion modulator.

The fabrication of horizontal and interleaved junction devices is more straightforward and they can be based in a conventional rib waveguide structure as electrical contacts can be formed through the slab regions on either side of the waveguide.

\section{Current research trends}

It can be seen that the performance of phase modulators has improved dramatically in recent years. Devices with operation in excess of $40 \mathrm{Gbit} / \mathrm{s}{ }^{32} 41495356$, phase efficiencies below $1 \mathrm{~V} . \mathrm{cm}^{58}$, power consumption down to $2 \mathrm{fJ} / \mathrm{bit}^{59}$ and loss at $1 \mathrm{~dB} / \mathrm{mm}$ and below ${ }^{51} 4353$ have been demonstrated although not with all these parameters together. Continual improvements in the device performance are still regularly being reported. Whilst work is on-going in improving the performance of the phase modulator element, research is also active on of some emerging research areas and challenges for silicon optical modulators. A few examples of that work are included here.

\subsection{Silicon based carrier depletion optical modulators for longer haul applications}

Silicon photonics is mainly seen as a technology for short reach links. This is due to demanding performance requirements and the high performance of components formed in more traditional photonic materials such as $\mathrm{LiNbO}_{3}$ which are used for longer reach links. As the performance of the silicon optical modulator is ever improved, application in systems with longer transmission distances could be feasible in the future. For example commercial modulators used for longer haul links report extinction ratios in excess of $13 \mathrm{~dB}^{6061}$. Recently there have been demonstrations of extinction ratios 
in excess of $10 \mathrm{~dB}$ from silicon optical modulators ${ }^{64} 62$ with $18 \mathrm{~dB}$ demonstrated in one case at a data rate of $10 \mathrm{Gbit} / \mathrm{s}^{47}$. Several groups have now looked at using silicon modulators for long haul applications considering additional performance metrics which are not important for short reach links such as the modulation chirp 475842636465 . Plasma dispersion based silicon optical modulators could be problematic in terms of chirp they produce since a change in both real and imaginary parts of the refractive index occur with changes in free carrier density. In $\mathrm{LiNbO}_{3}$ modulators zero chirp Mach-Zehnder modulators can be achieved by balancing the optical power in the two waveguide arms and applying synchronised but complementary signals of the same amplitude in either arm (dual-drive operation). Since the phase movements in either arm cancel and the optical power from either arm is the same no movement of the output phase occurs. The accompanying modulation of the optical power in the silicon phase modulator means that it is not possible to balance the optical power in either arm during modulation and therefore a change in the Mach-Zehnder Interferometer output phase with time will occur (chirp). The chirp from dual-drive silicon Mach-Zehnder modulators has been studied by different groups to assess if its impact is significant. In our work $^{47}$ we confirm that some degree of chirp is produced in the dual-drive case however when the pulse propagation over fibre is compared to that of a totally un-chirped pulse its effect is negligible. This has also been confirmed by Goi et $\mathrm{al}^{64}$ who showed a low-dispersion-penalty over transmission lengths up to $80 \mathrm{~km}$ with a performance comparable to that of a commercial lithium-niobate modulator. Recently the use of more complex modulation formats from silicon optical modulators has also been the subject of investigation. For example modulation using DPSK ${ }^{66}$, QPSK $^{67}$, DQPSK $^{67}$, PDM-QPSK ${ }^{68}$ and PAM- $16^{69}$ has been demonstrated from silicon based optical modulators.

\subsection{Plasma dispersion based modulators for MID-IR}

In recent years there has been a growing interest in the use of group-IV materials for mid-infrared wavelength photonics ${ }^{70}$, motivated by possible applications in telecommunications in the 2.0-2.5 $\mu \mathrm{m}$ range, and at longer wavelengths in bio-chemical sensing, gas sensing and related applications. Research groups have begun to investigate modulation in silicon in the mid-IR.

For NIR wavelengths the Soref and Bennett equations ${ }^{71}$ are used for predicting the size of the freecarrier plasma dispersion effect in silicon, but as the effect is wavelength dependent those equations cannot be used in the mid-IR. Nedeljkovic et al. ${ }^{72}$ have calculated predictions for the change in refractive index and change in absorption coefficient for a given change in charge carrier concentration at wavelengths in the 1.3-14 $\mu \mathrm{m}$ range, using the same semi-empirical approach used by Soref and Bennett. The change in absorption coefficient was calculated from the absorption spectra of heavily doped silicon wafers found in literature, and the change in refractive index was derived from the change in absorption spectra by way of the Kramers-Kronig relations. They found that the size of the effect is approximately proportional to $\lambda^{2}$, as described by the Drude-Lorentz model. They predict that for modulators operating at $\lambda>4 \mu \mathrm{m}$ it would be more effective to depart from NIR modulator design where phase modulators used in conjunction with a passive structure to convert to intensity modulation, and to use electro-absorption modulators, where modulation is provided by the change in absorption coefficient directly, such as simple charge-carrier injection into a straight waveguide.

Researchers at IBM have demonstrated the first SOI modulator operating at $2165 \mathrm{~nm}^{73}$, which is based on carrier-injection in a Mach-Zehnder interferometer, with $1 \mathrm{~mm}$ long $p$-i-n diode phase shifters in each arm. Using pre-emphasis they achieve bitrates up to $3 \mathrm{Gbps}$, an insertion loss of $9.0 \mathrm{~dB}$ and a $\mathrm{V} \pi \mathrm{L}$ figure of merit of $0.012 \mathrm{~V} . \mathrm{cm}$. The rib waveguides were similar to those common in NIR devices (width $\times$ height $=500 \times 220 \mathrm{~nm}$, with $170 \mathrm{~nm}$ etch depth). The authors do not compare their results to the modulation predictions in [72].

\subsection{Silicon based carrier depletion modulator for short reach links.}


As discussed in section 4.1 the target application areas for silicon photonics are in shorter reach links where the performance requirements are relaxed from those required for traditional long haul photonic links. The power consumption becomes a key concern especially as the link reach is decreased and the density of links increases. In recent years producing low power consumption silicon optical modulators has been a focus area for many groups who have followed different routes. As was discussed in section 2 the length of a typical Mach-Zehnder based carrier depletion modulator requires travelling wave electrodes to be used with a $50 \mathrm{Ohm}$ termination. Any power not consumed by the modulator will be dissipated in the termination and therefore only the drive voltage (and termination impedance) dictate the power consumption of the device. If it is not practical to employ a DC block between the device and the termination, additional DC power consumption should be avoided by operating around zero volts with an RF drive amplitude which is low enough not to cause the device to go into the carrier injection regime. This approach has been followed by Ding et al. where a power consumption of $146 \mathrm{fJ} / \mathrm{bit}$ was achieved ${ }^{39}$. The key in these devices is to use highly efficient phase modulators in order to produce a sufficient modulation depth with a lower drive voltage. Employing a slow light waveguide in which to produce the phase modulator is one possibility to achieve a high efficiency ${ }^{4074}$. Dispersion engineering can be used to mitigate against the problem of wavelength and temperature sensitivity which these devices usually suffer from to some extent ${ }^{74}$.

A more popular technique is to use a resonant structure in which the phase modulator is fabricated, for example a ring or a disk resonator. These devices produce intensity modulation by shifting the resonance wavelength on and off the input wavelength through operation of the phase modulator. Since the device can be driven as a lumped element, no termination is required and therefore power dissipation in the termination is avoided. Several examples of low power and high speed resonant

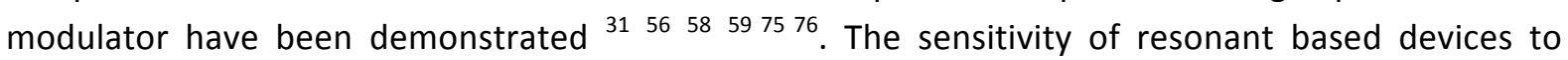
fabrication variations and temperature changes require them to be actively tuned to fix the resonance wavelength as required. Athermal techniques can be used to avoid the resonance wavelength shifting with temperature ${ }^{77}$, however this prevents thermal tuning being used to counter fabrication variations. Active tuning can be performed by incorporating a heater as demonstrated by $\mathrm{Li}$ et al. ${ }^{31}$ or by adding a controllable DC level to the RF drive voltage if the modulator is efficient enough and the tuning range required is sufficiently small ${ }^{78}$. An important consideration is the power consumption of the tuning element itself and therefore the efficiency of the different heater architectures possible ${ }^{79}$, and methods to improve the efficiency ${ }^{80}$, have attracted increasing research interest recently.

\subsection{Integration of silicon photonic modulators and detectors.}

One of the key cited advantages of silicon photonics is the potential to co-fabricate electronic and photonic elements on the same piece of silicon ${ }^{81}$. Such an approach is technologically elegant and also has the potential for optimised performance since any degradation introduced by the electrical connections between different chips should be eliminated. One example of this approach is that followed by Luxtera in the fabrication of their Active optical cables ${ }^{82}$. The drawback to such an approach is the high per-area cost of high performance electronic processing and the relative large size of the photonics elements. There is also the complexity of combining the processes for the photonic and electronic components without affecting device performance and the consideration of the required substrate in each case. A more cost effective and less complex strategy could be to 
separately fabricate photonic and electronic chips and then to integrate them by a wire bonding or flip chip bonding approach. The photonic chip can therefore be fabricated in a lower specification fabrication facility at lower cost.

Wire bonded integration is often referred to as an approach limited to low speed applications. The parasitic inductance introduced by the bonding wire and parasitic capacitance introduced by the bonding pads may reduce the bandwidth of the link and cause an impedance discontinuity. Within the UK Silicon Photonics programme the wire bonded approach for integrated silicon photonic transmitters and receivers operating up to $10 \mathrm{Gbit} / \mathrm{s}$ has been investigated.

Figure 11 shows a optical microscope image of the integrated transmitter modules which has been assembled. The image on the left shows a CMOS modulator driver and a silicon optical MachZehnder Interferometer modulator. The modulator incorporates $3.5 \mathrm{~mm}$ long carrier depletion based phase modulators in either arm. Coplanar waveguide (CPW) electrodes are used to co-propagate the $10 \mathrm{Gbit} / \mathrm{s}$ electrical drive signal with the light in the optical waveguide. At the end of phase shifters the CPW electrodes are tapered to facilitate wire bonding. The dual drive CMOS driver was fabricated using the IBM-8RF $130 \mathrm{~nm}$ process ${ }^{83}$. The image on the right shows a trans-impedance amplifier wire bonded with a germanium optical detector. The TIA was fabricated using the $180 \mathrm{~nm}$ TSMC technology ${ }^{84}$ and the detector fabricated at CEA-LETI ${ }^{85}$.

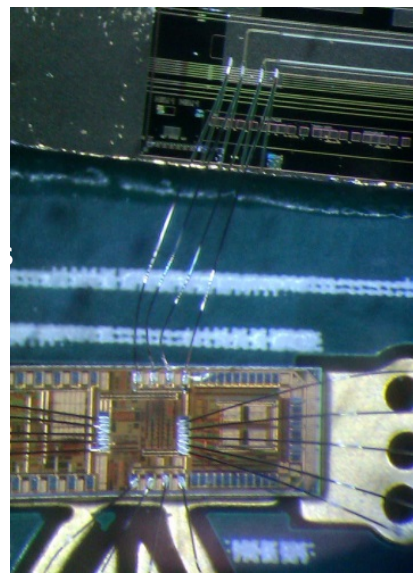

Figure 11 - Optical microscope image of the wire bonded carrier depletion modulator and CMOS driver.
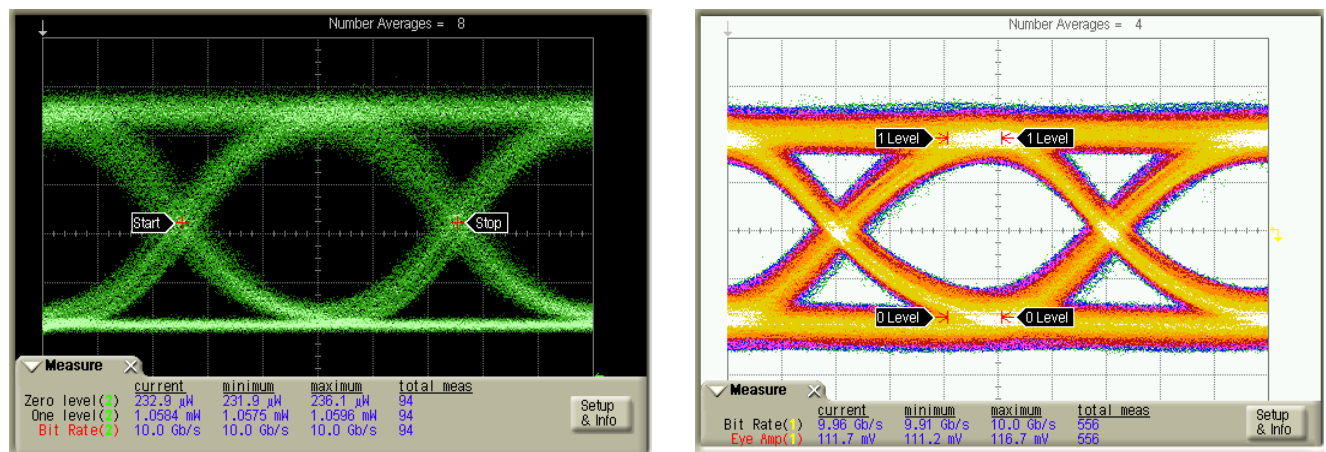

Figure $12-10 \mathrm{Gbit} / \mathrm{s}$ Optical eye diagram from the wire bond integrated silicon optical modulator and CMOS driver (left) and 10Gbit/s electrical eye diagram from the wire bond integrated optical detector and transimpeadance amplifier (right).

The transmitter was tested by applying complementary 10Gbit/s data signals to the input of the CMOS driver. CW laser light of $1551.38 \mathrm{~nm}$ was then passed to the input of the modulator via surface grating couplers. The output of the modulator was passed to a Digital Communcations Analyser (DCA) via an erbium doped fibre amplifier (EDFA) and bandpass optical filter. The output optical eye diagram as recorded by the DCA is shown in the left image of figure 12 . When the noise generated 
by the EDFA is subtracted from the 1 and 0 levels an extinction ratio of $9.8 \mathrm{~dB}$ results. The receiver was tested by applying an optical $10 \mathrm{Gbit} / \mathrm{s}$ signal generated by a commercial $\mathrm{LiNbO}_{3}$ modulator to the detector. The output of the TIA was then passed to the electrical input of the DCA. The eye diagram with amplitude $110 \mathrm{mV}$ is shown in the right image of figure 12.

From this it can be seen that wire bonds have the ability to be used for the integration of $10 \mathrm{Gbit} / \mathrm{s}$ elements. If the lengths of the wire bond are minimised then higher speed operation should also be possible; indeed it has been shown elsewhere that wire bond integration of silicon photonics can operate at $25 \mathrm{Gbit} / \mathrm{s}^{86}$. It should be noted in this case the limitation in the speed was set by the electronic elements and the detector which were designed to operate up to $10 \mathrm{Gbit} / \mathrm{s}$.

\section{Summary}

We have presented and provided published examples of three different configurations of carrier depletion phase modulator in silicon, as well as devices which are a mixture of these configurations. Each category of the device contains several degrees of freedom in the design which can be used to tailor a profile of performance metrics as required for a specific application. There are however some distinct advantages and disadvantages to each approach which are summarised herein.

Horizontal and interleaved junction devices can be electrically contacted via the slab regions on either side of a conventional rib waveguide, whereas the vertical junction device requires contact to the top of the waveguide. This means that the use of a conventional rib waveguide is not possible in the case of a vertical junction device and that a growth process is required in the fabrication which is more complex than the implantation approaches used to form the other two configurations of device.

Interleaved devices with high $\mathrm{p}$ and $\mathrm{n}$ type doping concentrations can theoretically be fully depleted if the period of the interleaving can be made small enough. This means that highly efficient devices can be made with low absorption loss. In highly doped vertical and horizontal junction devices, carriers far from the junction remain undepleted and therefore cause high optical losses limiting the achievable efficiency. Doping localisation methods can be used to overcome this to some extent at the expense of fabrication complexity.

The intrinsic bandwidth of the phase modulator element is dictated by the access resistance and junction capacitance. The power consumption of the device can also be influenced by the junction capacitance depending on how it is driven. The device capacitance which causes efficient modulation (or the capacitance-efficiency product) is theoretically higher (or worse) in interleaved devices since regions at the edges of the waveguide where low optical power is propagating, undergo the same depletion as at the core. Doping localisation methods can again be used to counteract this to some extent. In each category of device the access resistance can be kept low by keeping the contacts in close proximity to the waveguide whilst not introducing significant overlap with the optical mode which would result in high optical losses. The doping levels in the slab regions which connect to the device should also be kept sufficiently high in order to avoid high access resistance.

Vertical and interleaved junction devices have a further advantage of being inherently alignment tolerant which simplifies fabrication; however self-aligned processes can be used to produce horizontal devices with relaxed alignment demands.

Devices which mix the different junction types can bring about further advantages, for example, by combining an interleaved and horizontal junction device in way such that the pn junction is corrugated along the centre of the waveguide, the efficiency of the horizontal device can be improved. 
Some excellent device performance has been demonstrated in the literature in recent years, with operation in excess of $40 \mathrm{Gbit} / \mathrm{s}$, phase efficiencies below $1 \mathrm{~V} . \mathrm{cm}$, power consumption down to $2 \mathrm{fJ} / \mathrm{bit}$ and loss at $1 \mathrm{~dB} / \mathrm{mm}$ and below demonstrated (although not simultaneously), confirming the carrier depletion optical modulator as an increasingly promising approach. Improving the performance of the carrier depletion modulator is however an on-going challenge. A device which combines high efficiency, low optical loss and high speed simultaneously is still sought after. At the same time significant research effort is devoted to the integration of the carrier depletion silicon optical modulator with electronics and other photonic components.

There are several approaches and challenges for integrating electronics with photonics. Front-end integration where the electronics and photonics are formed side by side on the same wafer offers the prospect of the best performance, however the cost and complexity are high and integration density low. A back-end approach where the photonic components are formed using process temperature low enough to not damage the pre-fabricated electronics can be used, however, the performance of the photonic components formed in this way are generally inferior. A back-end wafer bonding approach can be used to affix pre-processed electronics and photonics wafers, the performance of the resultant electrical connections between the two wafers and the yield of the bonding process require consideration. Flip chip and wire bonding can also be used, however, the parasitic capacitance and inductance introduced by these approaches could degrade and limit the performance to some extent. A $10 \mathrm{Gbit} / \mathrm{s}$ wire bond integrated silicon photonic transmitter and receiver have been presented in this work. Furthermore a $25 \mathrm{Gbit} / \mathrm{s}$ wire bond integrated photonic link has been demonstrated in the literature.

Carrier depletion based silicon optical modulators remain a strong candidate for use in the growing number of short reach photonic applications and possibly even some longer reach links. Novel design features are continuously being introduced which are yielding on going improvements in the device performance. With the significant worldwide resources now devoted to research in this area it is clear that there is more to come from the carrier depletion silicon optical modulator into the future.

\section{Acknowledgements}

Authors acknowledge funding from the EPSRC in the UK to support the UK Silicon Photonics project.

\section{References}

\footnotetext{
${ }^{1}$ Y. Tang, J. D. Peters and J. E. Bowers, "Over $67 \mathrm{GHz}$ bandwidth hybrid silicon electroabsorption modulator with asymmetric segmented electrode for $1.3 \mu \mathrm{m}$ transmission," Optics Express, vol. 20, $\mathrm{n}$. 10, pp. 11529-11535, 2012.

${ }^{2}$ E. H. Edwards, L. Lever, E. T. Fei, T. I. Kamins, Z. Ikonic, J. S. Harris, R. W. Kelsall and D. A. B. Miller, "Low-voltage broad-band electroabsorption from thin Ge/SiGe quantum wells epitaxially grown on silicon," Optics Express, vol. 21, n. 1, pp.867-876, 2013.

${ }^{3}$ P. Chaisakul, D. Marris-Morini, M.-S. Rouifed, G. Isella, D. Chrastina, J. Frigerio, X. Le Roux, S. Edmond, J.-R. Coudevylle, and L. Vivien "Ge/SiGe multiple quantum well electro-absorption modulator," Optics Express, vol. 20, n. 3, pp. 3219-3224, 2012.

${ }^{4}$ L. Lever, Y. Hu, M. Myronov, X. Liu, N. Owens, F. Y. Gardes, I. P. Marko, S. J. Sweeney, Z. Ikonic, D. R. Leadley, G. T. Reed, and R. W. Kelsall, "Modulation of the absorption coefficient at 1.3 um in Ge/SiGe multiple quantum well heterostructures on silicon," Optics Letters, vol. 36, pp. 4158-4160, 2011. ${ }^{5}$ D. Feng, S. Liao, H. Liang, J. Fong, B. Bijlani, R. Shafiiha, B. J. Luff, Y. Luo, J. Cunningham, A. V. Krishnamoorthy, and M. Asghari, "High speed GeSi electro-absorption modulator at $1550 \mathrm{~nm}$ wavelength on SOI waveguide," Optics Express, Vol. 20, n. 20, pp. 22224-22232, 2012.
} 
${ }^{6}$ L. Ya-Ming, H. Wei-Xuan, C. Bu-Wen, L. Zhi and W. Qi-Ming, "Remarkable Franz-Keldysh Effect in Ge-on-Si p-i-n Diodes," Chinese Physics Letters, vol. 29, n. 3, pp. 034205-1 - 034205-3, 2012.

${ }^{7}$ L. Alloatti, D. Korn, R. Palmer, D. Hillerkuss, J. Li, A. Barklund, R. Dinu, J. Wieland, M. Fournier, J. Fedeli, H. Yu, W. Bogaerts, P. Dumon, R. Baets, C. Koos, W. Freude, and J. Leuthold, " $42.7 \mathrm{Gbit} / \mathrm{s}$ electro-optic modulator in silicon technology," Optics Express, vol. 19, n. 12, pp. 11841-11851, 2011. ${ }^{8}$ M. Gould, T. Baehr-Jones, R. Ding, S. Huang, J. Luo, A. K.-Y. Jen, J.-M. Fedeli, M. Fournier, and M. Hochberg, "Silicon-polymer hybrid slot waveguide ring-resonator modulator," Optics Express, vol. 19, n. 5, pp. 3952-3961, 2011.

${ }^{9}$ M. Liu, X. Yin, E. Ulin-Avila, B. Geng, T. Zentgraf, L. Ju, F. Wang and X. Zhang, "A graphene-based broadband optical modulator," Nature, vol. 474, pp. 64-67, 2011.

${ }^{10} \mathrm{M}$ Liu, X Yin and X Zhang, "Double-layer graphene optical modulator," Nano letters, vol. 12, n. 3, pp. 1482-1485, 2012.

${ }^{11}$ Z. Lu and W. Zhao, "Nanoscale electro-optic modulators based on graphene-slot waveguides," JOSA B, vol. 29, n. 6, pp. 1490-1496, 2012.

${ }^{12}$ C. Xu, Y. Jin, L. Yang, J. Yang, and X. Jiang, "Characteristics of electro-refractive modulating based on Graphene-Oxide-Silicon waveguide," Optics Express, vol. 20, n. 20, pp. 22398-22405, 2012.

${ }^{13}$ X. Gan, R.-J. Shiue, Y. Gao, K. F. Mak, X. Yao, L. Li , A. Szep, D. Walker Jr, J. Hone, T. F. Heinz, and D. Englund, "High-Contrast Electrooptic Modulation of a Photonic Crystal Nanocavity by Electrical Gating of Graphene," Nano Letters, vol. 13, n. 2, pp. 691-696, 2013.

${ }^{14}$ A. Melikyan, N. Lindenmann, S. Walheim, P. M. Leufke, S. Ulrich, J. Ye, P. Vincze, H. Hahn, Th. Schimmel, C. Koos, W. Freude, and J. Leuthold, "Surface plasmon polariton absorption modulator," Optics Express, vol. 19, n. 9, pp. 8855-8869, 2011.

${ }^{15}$ X. Sun, L. Zhou, X. Li, Z. Hong, and J. Chen, "Design and analysis of a phase modulator based on a metal-polymer-silicon hybrid plasmonic waveguide," Applied Optics, vol. 50, n. 20, pp. 3428-3434, 2011.

${ }^{16}$ V. J. Sorger, N. D. Lanzillotti-Kimura, R.-M. Ma and X. Zhang, "Ultra-compact silicon nanophotonic modulator with broadband response," Nanophotonics, vol. 1, n. 1, pp. 17-22, 2012.

${ }^{17}$ R. Thomas, Z. Ikonic and R. W. Kelsall, "Electro-optic metal - insulator - semiconductor insulator - metal Mach-Zehnder plasmonic modulator," Photonics and Nanostructures -

Fundamentals and Applications, vol. 10, n. 1, pp. 183-189, 2012.

${ }^{18}$ P. Pepeljugoski, J. Kash, F. Doany, D. Kuchta, L. Schares, C. Schow, M. Taubenblatt, B. J. Offrein and A. Benner, "Low Power and High Density Optical Interconnects for Future Supercomputers," Proceedings of Optical Fiber Communication Conference, OThX2, 2010.

${ }^{19}$ A. V. Krishnamoorthy, R> Ho, B. O'Krafka, J. E. Cunningham, J. Lexau and X. Zheng, "Potentials of Group IV Photonics Interconnects for "Red-shift" Computing Applications," Proceedings of IEEE Group IV Photonics 2007.

${ }^{20}$ T. Barwicz, H. Byun, F. Gan, C. W. Holzwarth, M. A. Popovic, P. T. Rakich, M. R. Watts, E. P. Ippen, F. X. Kärtner, H. I. Smith, J. S. Orcutt, R. J. Ram, V. Stojanovic, O. O. Olubuyide, J. L. Hoyt, S. Spector, M. Geis, M. Grein, T. Lyszczarz, and J. U. Yoon, "Silicon photonics for compact, energy-efficient interconnects," Journal of Optical Networking, vol. 6, n. 1, pp. 63-73, 2007.

${ }^{21}$ S. J. B. Yoo, "Future prospects of silicon photonics in next generation communication and computing systems," Electronics Letters, vol. 45, n. 12, pp. $584-588,2009$.

${ }^{22}$ K. Debnath, L. O'Faolain, F. Y. Gardes, A. G. Steffan, G. T. Reed, and T. F. Krauss, "Cascaded modulator architecture for WDM applications," Optics Express, vol. 20, n. 25, pp.27420-27428, 2012.

${ }^{23}$ B. Guha, A. Gondarenko and M. Lipson, "Minimizing temperature sensitivity of silicon MachZehnder interferometers," Optics Express, vol. 18, n. 3, pp.1879-1887, 2010.

${ }^{24}$ M. M. Milosevic, N. G. Emerson, F. Y. Gardes, X. Chen, A. A. D. T. Adikaari, and G. Z. Mashanovich, "Athermal waveguides for optical communication wavelengths," Optics Letters, vol. 36, pp. 46594661, 2011. 
${ }^{25}$ F. Gardes, G. Reed, N. Emerson, C. Png, "A sub-micron depletion-type photonic modulator in Silicon On Insulator," Optics Express, vol. 13, n. 22, pp.8845-8854, 2005.

${ }^{26}$ A. Liu, L. Liao, D. Rubin, H. Nguyen, B. Ciftcioglu, Y. Chetrit, N. Izhaky, and M. Paniccia, "High-speed optical modulation based on carrier depletion in a silicon waveguide," Optics Express, vol. 15 , n. 2, pp.660-668, 2007.

${ }^{27}$ L. Liao, A. Liu, D. Rubin, J. A. B. J. Basak, Y. A. C. Y. Chetrit, H. A. N. H. Nguyen, R. A. C. R. Cohen, N. A. I. N. Izhaky, and M. A. P. M. Paniccia, "40 Gbit/s silicon optical modulator for highspeed applications," Electronics Letters, vol. 43, 2007.

${ }^{28}$ S. J. Spector, M. W. Geis, M. E. Grein, R. T. Schulein, J. U. Yoon, D. M. Lennon, F. Gan, G-R. Zhou, F. X. Kaertner, and T. M. Lyszczarz "High-speed silicon electro-optical modulator that can be operated in carrier depletion or carrier injection mode," 2008 Conference on Lasers and Electro-Optics (CLEO), 2008.

${ }^{29}$ D. Marris-Morini, L. Vivien, J-M. Fédéli, E. Cassan, P. Lyan, S. Laval "Low loss and high speed silicon optical modulation based on a lateral carrier depletion structure," Opt. Express, vol. 16, n. 1, pp. 334-339, 2008.

${ }^{30}$ J-B. You, M. Park, J-W. Park and G. Kim "12.5 Gbps optical modulation of silicon racetrack resonator based on carrier-depletion in asymmetric p-n diode," Opt. Express, vol. 16, n. 22, pp. 18340-18344, 2008.

${ }^{31}$ G. Li, X. Zheng, H. Thacker, J. Yao, Y. Loo, I. Shubin, K. Raj, J. E. Cunningham, and A. V. Krishnamoorthy, "40Gb/s thermally tunable CMOS ring modulator," Proceedings of Group IV photonics 2012.

32 P. Dong, L. Chen, and Y-K. Chen, "High-speed low-voltage single-drive push-pull silicon MachZehnder modulators," Opt. Express, vol. 20, n. 6, pp. 6163-6169, 2012.

${ }^{33}$ T. Baehr-Jones, R. Ding, Y. Liu, A. Ayazi, T. Pinguet, N. C. Harris, M. Streshinsky, P. Lee, Y. Zhang, A. E-J. Lim, T-Y. Liow, S. H-G. Teo, G. Q. Lo, and M. Hochberg, "Ultralow drive voltage silicon travelingwave modulator," Opt. Express, vol. 20, n. 11, pp. 12014-12020, 2012.

${ }^{34}$ D. Korn, Y. Hui, D. Hillerkuss, L. Alloatti, C. Mattern, K. Komorowska, W. Bogaerts, R. Baets, J. Van Campenhout, P. Verheyen, J. Wouters, M. Moelants, P. Absil, C. Koos, W. Freude and J. Leuthold, "Detection or modulation at $35 \mathrm{Gbit} / \mathrm{s}$ with a standard CMOS-processed optical waveguide," Proceedings of Conference on Lasers and Electro-Optics (CLEO), 2012.

${ }^{35} \mathrm{H}$. Yu, W. Bogaerts, K. Komorowska, J. Van Campenhout, P. Verheyen, P. P. Absil and R. Baets, "12.5 Gbits/s carrier-depletion based silicon Mach-Zehnder modulation with a 2 V driven voltage," Proceedings of the 2011 annual symposium of the IEEE Photonics Benelux Chapter. p.93-96, 2011. ${ }^{36}$ G. Kim, J. Woo Park, I. G. Kim, S. Kim, S. Kim, J. M. Lee, G. S. Park, J. Joo, K-S. Jang, J. H. Oh, S. A. Kim, J. H. Kim, J. Y. Lee, J. M. Park, D-W. Kim, D-K. Jeong, M-S. Hwang, J-K. Kim, K-S. Park, H-K. Chi, HC. Kim, D-W. Kim, and M. H. Cho, "Low-voltage high-performance silicon photonic devices and photonic integrated circuits operating up to $30 \mathrm{~Gb} / \mathrm{s}$," Opt. Express, vol. 19, n. 27, pp. 26936-26947, 2011.

${ }^{37}$ X. Li, X. Xiao, H. Xu, Z. Li, T. Chu, J. Yu and Y .Yu, "Highly Efficient Silicon Michelson Interferometer Modulators," IEEE Photonics technology Letters, vol. 25, n. 5, 2013.

${ }^{38}$ H. Yu, M. Pantouvaki, J. Van Campenhout, D. Korn, K. Komorowska, P. Dumon, Y. Li, P. Verheyen, P. Absil, L. Alloatti, D. Hillerkuss, J. Leuthold, R. Baets and W. Bogaerts, "Performance tradeoff between lateral and interdigitated doping patterns for high speed carrier depletion based silicon modulators," Optics Express, vol. 20, n. 12, pp. 12926-12938, 2012.

${ }^{39}$ J. Ding, H. Chen, L. Yang, L. Zhang, R. Ji, Y. Tian, W. Zhu, Y. Lu, P. Zhou, R. Ming and M. Yu, "Ultralow-power carrier-depletion Mach-Zehnder silicon optical modulator," Optics Express, vol. 20, n. 7, pp. 7081-7087, 2012.

${ }^{40}$ A. Brimont, D. J. Thomson, P. Sanchis, J. Herrera, F. Y. Gardes, J. M. Fedeli, G. T. Reed, and J. Marti, "High speed silicon electro-optical modulators enhanced via slow light propagation," Optics Express, vol. 19, pp. 20876-20885, 2011 
${ }^{41}$ X. Xiao, H. Xu, X. Li, Z. Li, T. Chu, Y. Yu, and J. Yu, "High-speed, low-loss silicon Mach-Zehnder modulators with doping optimization," Opt. Express, vol. 21, n. 4, pp. 4116-4125, 2013.

${ }^{42} \mathrm{H}$. Yi, Q. Long, W. Tan, L. Li, X. Wang, and Z. Zhou, "Demonstration of low power penalty of silicon Mach-Zehnder modulator in long haul transmission," Optics Express, vol. 20, n. 25, pp. 27562-27568, 2012.

${ }^{43}$ X. Tu, T. Liow, J. Song, X. Luo, Q. Fang, M. Yu, and G. Lo, "50-Gb/s silicon optical modulator with traveling-wave electrodes," Opt. Express 21(10), 12776-12782, 2013.

${ }^{44}$ F. Y. Gardes, A. Brimont, P. Sanchis, G. Rasigade, D. Marris-Morini, L. O'Faolain, F. Dong, J-M. Fedeli, P. Dumon, L. Vivien, T. F. Krauss, G. T. Reed and J. Martí "High-speed modulation of a compact silicon ring resonator based on a reverse-biased pn diode," Opt. Express, 17(24), 2198621991, 2009.

${ }^{45}$ D. J. Thomson, F. Y. Gardes, G. T. Reed, F. Milesi, and J-M Fedeli "High speed silicon optical modulator with self aligned fabrication process," Opt. Express, 18(18), 19064-19069, 2010.

${ }^{46}$ F. Y. Gardes, D. J. Thomson, N. G. Emerson, and G. T. Reed, " $40 \mathrm{~Gb} / \mathrm{s}$ silicon photonics modulator for TE and TM polarisations," Opt. Express, 19(12), pp. 11804-11814, 2011.

${ }^{47}$ D. J. Thomson, F. Y. Gardes, S. Liu, H. Porte, L. Zimmermann, J-M Fedeli, Y. Hu, M. Nedeljkovic, X. Yang, P. Petropoulos and G. Z. Mashanovich, "High Performance Mach Zehnder Based Silicon Optical Modulators," IEEE Journal of Selected Topics in Quantum Electronics, vol. 19, n. 6, 2013.

${ }^{48}$ D. J. Thomson, F. Y. Gardes, Y. Hu, G. Mashanovich, M. Fournier, P. Grosse, J-M. Fedeli and G. T. Reed, "High contrast 40Gbit/s optical modulation in silicon," Optics Express, vol. 19, n. 12, pp. 11507-11516, 2011.

${ }^{49}$ D. J. Thomson, F. Y. Gardes, J-M. Fedeli, S. Zlatanovic, Y. Hu, B. P. -P. Kuo, E. Myslivets, N. Alic, S. Radic, G. Z. Mashanovich and G. T. Reed, "50Gb/s Silicon Optical Modulator," IEEE Photonics Technology Letters, vol. 24, n. 4, pp. 234-236, 2012.

${ }^{50}$ T-Y Liow, J. Song, X. Tu, A. E-J. Lim, Q. Fang, N. Duan, M. Yu and G-Q. Lo, "Silicon Optical Interconnect Device Technologies for $40 \mathrm{~Gb} / \mathrm{s}$ and Beyond," IEEE Journal of Selected topics in Quantum electronics, vol. 19, n. 2, 2013.

${ }^{51}$ M. Ziebell, D. Marris-Morini, G. Rasigade, J-M. Fédéli, P. Crozat, E. Cassan, D. Bouville, and L. Vivien, "40 Gbit/s low-loss silicon optical modulator based on a pipin diode," Opt. Express, vol. 20, n. 10, pp. 10591-10596 2012.

${ }^{52}$ Z-Y. Li, D-X. Xu, R. W. McKinnon, S. Janz, J. H. Schmid, P. Cheben and J-Z. Yu, "Silicon waveguide modulator based on carrier depletion in periodically interleaved PN junctions," Opt. Express, vol. 17, n. 18, pp.15947-15958, 2009.

${ }^{53}$ H. Xu, X. Xiao, X. Li, Y. Hu, Z. Li, T. Chu, Y. Yu and J. Yu, "High speed silicon Mach-Zehnder modulator based on interleaved PN junctions," Optics Express, vol. 20, n. 14, pp.15093-15099, 2012.

${ }^{54}$ X. Xiao, H. Xu, X. Li, Y. Hu, K. Xiong, Z. Li, T. Chu, Y. Yu and J. Yu, "25 Gbit/s silicon microring modulator based on misalignment-tolerant interleaved PN junctions," Optics Express, vol. 30, n. 3, pp. 2507-2515, 2012.

${ }^{55}$ M. Ziebell, D. Marris-Morini, G. Rasigade, P. Crozat, J-M. Fedeli, P. Grosse, E. Cassan and L. Vivien, "Ten Gbit/s ring resonator silicon modulator based on interdigitated PN junctions," Optics Express, vol. 19, n. 15, pp. 14690-14695, 2011.

${ }^{56}$ X. Xiao, X. Li, Y. Hu, K. Xiong, Z. Li, T. Chu, J. Yu and Y. Yu, "44-Gb/s Silicon Microring Modulators Based on Zigzag PN Junctions," IEEE Photonics Technology Letters, vol. 24, n. 19, pp. 1712-1714, 2012.

${ }^{57}$ S. J. Spector, C. M. Sorace, M. W. Geis, M. E. Geis, M. E. Grein, J. U. Yoon, T. M. Lyszczarz, E. P. Ippen and F. X. Kartner, "Operation of Silicon-Diode-Based Optical Modulators," IEEE Journal of Selected Topics in Quantum Electronics, vol. 16, n. 1, pp.165-172, 2010.

58 J. C. Rosenberg, W. M. J. Green, S. Assefa, D. M. Gill, T. Barwicz, M. Yang, S. M. Shank and Y. A. Vlasov, "A 25Gbps silicon microring modulator based on an interleaved junction," Optics Express, vol. 20, n. 24, pp.26411-26423, 2012. 
${ }^{59}$ W. A. Zortmann, A. L. Lentine, D. C. Trotter, and M. R. Watts. "Low-voltage differentially-signaled modulators,' Optics Express, vol. 19, n. 27, pp. 26017-26026, 2011.

${ }^{60} \mathrm{http}: / /$ www.photline.com/filer/get/14/ReviewModulSpecs.pdf

${ }^{61} \mathrm{http}: / /$ dev.oclaro.com/product_pages/Powerbit_F10-0.php

62 J. Ding, H. Chen, L. Yang, L. Zhang, R. Ji, Y. Tian, W. Zhu, Y. Lu, P. Zhou, and R. Min , "Low-voltage, high-extinction-ratio, Mach-Zehnder silicon optical modulator for CMOS-compatible integration," Opt. Express, vol. 20, n. 3, pp.3209-3218, 2012.

${ }^{63} \mathrm{~L}$. Chen, P. Dong, and Y-K. Chen, "Chirp and dispersion tolerance of a single-drive push-pull silicon modulator at 28Gb/s," IEEE Photonics Technology Letters, vol. 24, n. 11, pp. 936-938, 2012.

${ }^{64}$ K. Goi, K. Oda, H. Kusaka, Y. Terada, K. Ogawa, T-Y. Liow, X. Tu, G-Q. Lo, and D-L. Kwong "11-Gb/s 80-km transmission performance of zero-chirp silicon Mach-Zehnder modulator," Optics Express, vol. 20, n. 26, pp. B350-B356, 2012.

${ }^{65}$ Y. Wei, Y. Zhao, J. Yang, M. Wang, and X. Jiang "Chirp characteristics of silicon Mach-Zehnder modulator under small-signal modulation," IEEE Journal of Lightwave Technology, vol. 29, n.7, pp. 1011 - 1017, 2011.

${ }^{66}$ M. Aamera, D. J. Thomson, A. M. Gutiérrez, A. Brimont, F.Y. Gardes, G.T. Reed, J.M. Fedeli, A. Hakansson, and P. Sanchis, "10 Gbit/s error-free DPSK modulation using a push-pull dual-drive silicon modulator," Optics Communications, vol. 304, pp. 107-110, 2013.

${ }^{67}$ K. Goi, H. Kusaka, A. Oka, Y. Terada, K. Ogawa, T-Y Liow, X. Tu, G. Lo, and D-L Kwong, "DQPSK/QPSK Modulation at 40-60 Gb/s using Low-Loss Nested Silicon Mach-Zehnder Modulator," Proceedings of OFC, OW4J.4, 2013.

${ }^{68}$ P. Dong, C. Xie, L. Chen, L. L. Buhl, and Y-K. Chen, "12-Gb/s Monolithic PDM-QPSK Modulator in Silicon," Proceedings of ECOC, Postdeadline Session II (Th.3.B), 2012.

${ }^{69}$ X. Wu, B. Dama, P. Gothoskar, P. Metz, K. Shastri, S. Sunder, J. Van der Spiegel, Y. Wang, M. Webster and W. Wilson, "A 20Gb/s NRZ/PAM-4 1V Transmitter in 40nm CMOS Driving a Ai-Photonic Modulator in 0.13um CMOS," Proceedings of ISSCC, Session 7, 7.7, 2013.

${ }^{70}$ R. Soref, "Mid-infrared photonics in silicon and germanium", Nature Photonics, Vol.4, n. 8, 2010.

${ }^{71}$ R. A. Soref and B. R. Bennett, "Electrooptical effects in silicon," IEEE Journal of Quantum Electronics, vol. 23, n. 1, pp. 123-129, 1987.

${ }^{72}$ M. Nedeljkovic, R. Soref, and G. Z. Mashanovich, "Free-carrier electro-refraction and electroabsorption modulation predictions for silicon over the 1-14 um wavelength range," IEEE Journal of Photonics, vol. 3, n. 6, pp. 1171-1180, 2011.

${ }^{73}$ M.A. Van Camp, S. Assefa, D.M. Gill, T. Barwicz, P.M. Rice, T. Topuria, and W.M. Green, "Demonstration of electrooptic modulation at $2165 \mathrm{~nm}$ using a silicon Mach-Zehnder interferometer", Optics Express, vol.20, n. 27, pp. 28009-28016, 2012.

${ }^{74}$ H. C. Nguyen, S. Hashimoto, M. Shinkawa, and T. Baba, "Sub-100um, 40Gb/s Photonics Crystal Silicon Optical Modulators, Proceedings of IEEE Group IV Photonics 2012.

${ }^{75}$ D. J. Thomson, F. Y. Gardes, D. C. Cox, J-M. Fedeli, G. Z. Mashanovich, and G. T. Reed, "Self-aligned silicon ring resonator optical modulator with focused ion beam error correction," Journal of Optical Society of America B, vol. 30, n. 2, pp. 445-449, 2013.

${ }^{76}$ Y. Hu, X. Xiao, H. Xu, X. Li, K. Xiong, Z. Li, T. Chu, Y. Yu, and J. Yu, "High-speed silicon modulator based on cascaded microring resonators," Optics Express, vol. 20, n. 14, pp. 15079-15085, 2012.

${ }^{77}$ M. M. Milosevic, F. Y. Gardes, D. J. Thomson, G. Z. Mashanovich, "Temperature insensitive racetrack resonators for optical communication applications," OFC 2012, Los Angeles, USA, 4-8 March 2012.

${ }^{78}$ M. Georgas, J. Leu, B. Moss, C. Sun, and V. Stojanovic, "Addressing Link-Level Design Tradeoffs for Integrated Photonic Interconnects," IEEE Custom Integrated Circuits Conference (CICC), pp. 1-8, 2011. 
${ }^{79}$ A. Masood, M. Pantouvake, G. Lepage, P. Verheyen, J. Van Campenhout, P. Absil, D. Van Thourhout, and W. Bogaerts, "Comparison of heater Architectures for Thermal Control of Silicon Photonic Circuits," Proceedings of IEEE Group IV Photonics 2013.

${ }^{80}$ I. Shubin, X. Zheng, G. Li, H. Thacker, J. Yao, B. Guenin, T. Pinguet, A. Mekis, A. V. Krishnamoorthy and J. E. Cunningham, "Low Power Thermal Tuning of SOI-CMOS Photonic Sturctures, Proceedings of SPIE Photonics West 2011.

${ }^{81}$ G. T. Reed and A. P. Knights, Silicon Photonics: An Introduction, Wiley, Chichester, UK, 2004.

82 http://www.luxtera.com/

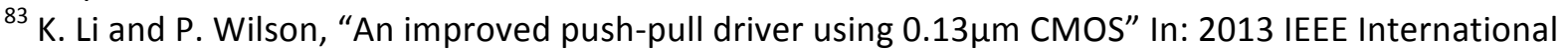
Symposium on Circuits and Systems, ISCAS, 2013.

${ }^{84}$ S. H. Hsu et al., "CMOS Broadband Amplifiers for Optical Communications and Optical Interconnects," IEEE Symposium of RF Integration Technology, 2011.

${ }^{85} \mathrm{http}: / /$ www.leti.fr/en

${ }^{86}$ S. Jatar, Y. Malinge, Z. Zhou, H. Liang, S. Lioa, Z. Li, C. Bushyakanist, D. C. Lee, R. Shafiiha, J. Luff, D. Feng and M. Asghari, "Performance of parallel $4 \times 25$ Gbs transmitter and receiver fabricated on SOI platform," Proceedings of IEEE Group IV Photonics 2012. 